\title{
Ultrasonic Modification of Selected Polysaccharides-Review
}

\section{Fredrick Onyango Ogutu ${ }^{1,2^{\star}}$, Tai-Hua Mu${ }^{1}$, Rizwan Elahi ${ }^{1}$, Miao Zhang ${ }^{1}$ and Hong-Nan Sun ${ }^{1}$}

${ }^{1}$ Laboratory of Food Chemistry and Nutritional Sciences, Institute of Agro-product products Processing Science and Technology of the Chinese Academy of Agricultural Sciences, Beijing, China

${ }^{2}$ Food Technology Division, Kenya Industrial Research and Development Institute (KIRDI), Nairobi-Kenya

\begin{abstract}
This review is a survey on ultrasonic application in selected carbohydrate polymers based upon available research reports. It covers a brief discussion on the fundamentals of ultrasound technology, before delving on the effects of ultrasound on specific polymers; pectin, chitin, starch, carrageenan and guar gum, their modification products and possible applications in food, pharmaceutical, biomedical and packaging sectors. Sonication generally leads to depolymerization and side chain break within molecules resulting into oligosugars. Oligosugars are widely used as prebiotics and specific delivery systems; moreover, nano sized products of sonication can be applied in diverse fields. Presently, ultrasonic is finding application in wider sectors therefore better understanding of the complex physico-chemical changes and mechanism of the action of high-intensity ultrasound and its effect on techno-functional properties of compounds would immensely fortify the application of ultrasonic technology.
\end{abstract}

Keywords: Sonication; Oligosaccharides; Cavitation;Depolymerization; Modification; Functional

\section{Introduction}

Carbohydrate polymers are the most abundant organic resources in nature with cellulose, chitin and starch being the most abundant, they consist of polymeric structures, formed by repeating units of monosaccharide joined together by 0 - glycosidic bonds [1]. Carbohydrate polymers are quite diverse based upon their monosaccharide composition, bond linkage type, branching, degrees of polymerization and cone shape [2]. The polymers are widely applied in food, cosmetic, pharmaceutical and others sectors [3-6].

The carbohydrate colloids are mainly applied in food as stabilizers, emulsifiers, thickening and texture improving agents $[7,8]$. The colloids application as food ingredient is based upon their physic-chemical characteristics, which often limit their application. To diversify the application of the colloids in food and functional food, modification is often required to achieve desired quality $[9,10]$. For instance, colloid size reduction has been shown to enhance stability in food a system that requires stabilization $[11,12]$.

Food ingredients and functional food sector has been growing from the macro scale molecules to micro and currently nano scale [1316]. While micro and nano-sized food particles are believed to have better absorption, stabilization ability and solubility etc. For instance starch nano crystals use as a reinforcing phase in a polymeric matrix and as a barrier material in packaging materials nano-emulsion was also shown to be effective carrier for hydrophobic bioactive molecules since novel ingredients can be added with negligible impact to solution clarity. For a long time enzymatic and chemical methods have been the preferred choice for molecular size reduction in colloids. However, due to the hazardous nature of chemicals and delicate control in enzymatic reactions the use of physical methods has been gaining ground [1719]. Ultrasonic method is emerging as an easily adaptable, easy to use and effective method of polymer modification as demonstrated by the numerous research reports [20-23]. The current review looked at research papers on sonication of pectin, carrageenan, chitosan, guar gum and starch. The aim was to give insight into sonolysis by extracting the documented pieces of evidence, with a view of aiding better understanding the underlying process, products and possible applications.
Ultrasonic is defined as the science and technology of applying sound waves with frequencies above human hearing ability, essentially above $20 \mathrm{kHz}$ [24]. Ultrasound can be classified into two main classes based upon frequency range i.e. power ultrasound and diagnostic ultrasound [25]. Power ultrasound is in the average range of $18-100 \mathrm{kHz}$ and intensity $>1 \mathrm{w} / \mathrm{m}^{2}$ which can be applied in processing and chemical transformation, while diagnostic ultrasound with frequency above 500 $\mathrm{MHz}$. Power ultrasound may also be referred to as Sonochemistry, which is the Ultrasound application in materials, chemical reaction and processes, excluding medical applications [26]. Another classification scheme categorizes ultrasound into three main classes based upon their frequency and power range as follows; low frequency high power ultrasound $20-10 \mathrm{kHz}$, medium frequency medium power ultrasound $100 \mathrm{kHz}-1 \mathrm{MHz}$ and the high frequency low power ultrasound $>1 \mathrm{MHz}$.

Ultrasound with high impact applied in the food industry is in the range of low and high frequency. However, this definition is steadily changing with increasing and expanding applications of ultrasound in areas like cleaning, measuring quality and flow rate of foods $[27,28]$. This paper reviews the available literature on the application of power ultrasound to selected carbohydrates polymer and its sonochemical impact.

\section{General Applications of Ultrasonic in Foods}

Ultrasound is a form of energy carried by sound and can be transformed into other forms energy which is the basis of its applications $[29,30]$. Power ultrasound is capable of causing physical and chemical transformations through acoustic cavitation [31]. Ultrasonic treatment requires fluid for cavitation to be generated; moreover, some conditions must be met, for instance the frequency must be between 20 to $100 \mathrm{kHz}$.

*Corresonding author: Fredrick Onyango Ogutu, Laboratory of Food Chemistry and Nutritional Sciences, Institute of Agro-product products Processing Science and Technology of the Chinese Academy of Agricultural Sciences, Beijing, China, Tel: +86 13021072954; E-mail: fogutu0@gmail.com

Received March 16, 2015; Accepted April 08, 2015; Published April 15, 2015

Citation: Ogutu FO, Mu T, Elahi R, Zhang M, Sun H (2015) Ultrasonic Modification of Selected Polysaccharides-Review. J Food Process Technol 6: 446 doi:10.4172/2157-7110.1000446

Copyright: ( $) 2015$ Ogutu FO, et al. This is an open-access article distributed unde the terms of the Creative Commons Attribution License, which permits unrestricted use, distribution, and reproduction in any medium, provided the original author and source are credited. 
Other conditions like solvent must meet required viscosity and polymer concentration should not be very high besides the solvent temperature should be low enough, approximately below $40^{\circ} \mathrm{C}[32]$.

Ultrasound is applied to food systems in the form of ultrasonic bath or probe [33]. Whereas in an ultrasonic bath, the solution of material to be sonicated is put in a container, thereafter the container is put in an ultrasonic bath with no direct contact between the material and equipment, in the ultrasonic probe, the probe is inserted in a container carrying the material allowing direct contact between the probe and the material [34]. The ultrasonic bath or probe creates cavitation in solution, owing to the formation of numerous water vapor bubbles which expand and contract rapidly, causing increased temperature and pressure up to $5000^{\circ} \mathrm{C}$ and 2000 bars respectively. Other forces that cause deformation is vibration, physical agitation and radical generation from the sonication fluid, water for instance is broken into $\mathrm{H}^{+}$and $0 \mathrm{H}^{-}$ions which are radicals [35].

\section{Ultrasonic machine}

Ultrasonic machine consists of the following key parts:

Sonotrode: Sonotrodes are often referred to as the horn. They come in different sizes and power ratings. The tip transfers the oscillations into the medium to be sonified; eventually power is transferred through sonotrode into the material to be deformed [36].

Transducer: Ultrasonic transducer is the part that converts electrical energy into high frequency sound, the most commonly used one is piezoelectric transducers, even though in some cases magnetostrictive transducers are also used. High intensity low frequency ultrasound generates acoustic waves which are transferred in fluids as cavitation capable of causing chemical, physical or mechanical transformation in systems by creating micro cavities in liquids, numerous bubbles are formed and they collapse, the collapse rate is approximately 10-6sec causing intense heating and high pressure $[37,38]$. Second mechanism involves electronic waves causing increases in the amount of reactive species within the system [39].

\section{Ultrasonic Power in Carbohydrate Polymer Degradation}

Power ultrasound performance depends upon specific factors which influence cavitation. They include frequency, solvent, intensity and temperature $[40,41]$.

\section{Ultrasonic intensity}

Ultrasound power is measured in watts; the absolute power equation is correlation between changes in temperature divided by change in time of a solvent system with specific heat capacity. The power equation was given by the following correlation:

Where $\mathrm{P}$ is absolute power (watts), " $\mathrm{T}$ " is temperature change, " $\mathrm{t}$ " is time difference, "Cp" is specific heat capacity of the solution and " $\mathrm{M}$ " is the mass of the solution.

The sonic intensity significantly contributes to ultrasonic effect in systems. For the probe type ultrasonic processor, the intensity of ultrasound power that is dissipated at the tip is predicted by the equation below [42].

\section{Frequency}

The frequency of ultrasound is believed to begin from $20 \mathrm{kHz}$, even though some authors state the minimum frequency is $\geq 16 \mathrm{kHz}$, the low frequency is able to generate cavitation's, heating and surface instability in fluids. High power ultrasound is in the low frequency range between $20-100 \mathrm{kHz}$, while the high frequency ultrasound with frequency $>500$ $\mathrm{MHz}$ is applied in diagnostic work. Power ultrasound is able to cause physical, chemical and biochemical effects, which makes it applicable in Sonochemistry and processing.

\section{Solvent}

Action of ultrasound greatly depends upon solvent choice; the most commonly used solvent is water because most of the compounds are water soluble. However, some compounds are hydrophobic hence organic solvents are used in such cases. Solvents viscosity and surface tension inhibits sonication, therefore solvents with low surface tension and viscosity are preferred [43].

\section{Temperature}

Temperature is a crucial factor in several physical, biological and chemical reactions. Enzymatic and chemical reactions are known to be temperature dependent $[44,45]$. Ultrasonic is equally affected by temperature, with lower temperatures favors sonication, at higher temperature cavitation's collapse less violently, essentially high sonication occurs between $5^{\circ} \mathrm{C}-45^{\circ} \mathrm{C}$ [46]. Effective sonication depends upon balance between cavitation and temperature [47]. Where " $\mathrm{I}$ " is ultrasound intensity, " $\mathrm{P}$ " is input power and " $\mathrm{r}$ " is radius of the probe.

\section{Mechanism of Polymer Sonication}

Carbohydrate polymers consist of complex macromolecular structures ranging from starch, chitin, cellulose, pectin, carrageen, guar gum, alginate, dextrin and hemicelluloses etc. These polymers have little shared properties besides the basic Carbon, hydrogen and oxygen constituents [48]. Sonication of polymers is related to the polymer length, concentration and type of solvent, frequency of sound and intensity of ultrasound. So far Ultrasound has been applied in modification of several carbohydrate polymers including dextran, starch and chitosan [49], hydroxyl propyl methyl cellulose [50], carboxyl methyl cellulose, high methoxyl pectin [51], Guar gum and carrageenan gum $[52,53]$.

While enzyme modification involves using different enzymes to break down specific bonds present in a polymer eg in pectin modification polygalacturonases are needed to depolymerize the Homogalacturonan chain, methylesterases are needed for demethylation and other enzymes to break specific bonds [54-57] similarly chemical method use specific chemicals which attack chemical bonds present in a polymer causing depolymerization [58]. These methods are laborious, expensive; require many cleaning steps and sometimes inefficient [59].

Generally, sonication breaks polymer chains at the center, which is the structurally weakest point. Molecules with high molecular weight and long chain length are more often broken at the center, than shorter and stiffer chains. Furthermore, the linear polymer chains are more easily sonolysed compared to branched ones. Therefore the initial molecular weight of the polymers plays an important role in the overall degradation rate. As polymers are broken down, a point is reached where the chains become so short and stiff, that further degradation is not possible and a lower molecular weight limit is attained [60]. The only way to overcome the lower limit is to increase the energy density of the sound field. It is worth noting that longer-chained molecules also lead to higher solution viscosity which also affects the rate of cavitation [61] 


\section{Sonication of pectin}

Pectin modification consists of a process or step in which the pectin structure, physical and chemical property is changed to suit a given application. Methods like chemical $[62,63]$, heat modification [64], irradiation [65] and enzymatic [66] have been applied in pectin modification. Sonication has been applied in pectin to a lesser extent with only handful of published papers to that effect $[67,68]$.

Mechanisms: Sonication of citrus pectin was reported and observed that the average molecular weight decreased from 464 to $296 \mathrm{k}$ Da after 30 minutes of treatment, degree of methylation reduced slightly, the neutral sugar side chain was degraded while the total monosaccharide content remained the same. The rate of pectin molecular weight degradation was predicted by the following equation

\section{$1 / \mathrm{Mt}-1 / \mathrm{M} 0=\mathrm{kt}$}

Where $\mathrm{k}$ is the rate constant $\left(\mathrm{mol} / \mathrm{g}^{*} \mathrm{~min}\right)$ of molecular weight during sonochemical degradation, where " $\mathrm{t}$ " is the sonochemical degradation time (min); "Mt" and "M0" are the weight-average molar mass at time $t$ and at time 0 (Daltons), respectively.

While sonicating citrus pectin Liu et al., noted decrease in the molecular weight of sonicated citrus pectin reduced from $630 \mathrm{k}$ Da to $230 \mathrm{k} \mathrm{Da}$, esterification degree and viscosity with increasing time from 0 to $90 \mathrm{~min}$, ultrasound intensity and ultrasound duty cycle. Optimum sonolysis was noted at sonication intensity $302 \mathrm{~W} / \mathrm{cm}^{2}$, above this intensity the sonolysis activity showed no significant change.

In a study on the effect of high-intensity ultrasound on the rheological and optical properties of high-esterified apple pectin dispersions, resulted in decreased turbidity, weaker gel and decreased in viscosity, which were attributed to decreased molecular weight at the highest intensity level of $40 \mathrm{Wcm}^{-2}$ in $30 \mathrm{~min}$. This is similar to other authors who showed decreasing molecular weight, viscosity and gel strength during sonication $[69,70]$.

Additionally, Sonication was applied in preparation of pectosomes and chitosomes for liposomes drug delivery system. The presence of pectin and chitin stabilized the retention of metronidazole; moreover, sonication of the liposomes resulted into nano-sized particles with size ranging from $62 \mathrm{~nm}-222 \mathrm{~nm}$ for freshly prepared liposomes after sonication.

Characteristics of sonicated pectin: The sonicated pectin products have been characterized by few authors. Some noted changes included reduced degree of polymerization, molecular weight, reduced DM and neutral sugar degradation. Sonication can be used to make micro and nano-sized pectin derivatives for different applications.

Potential applications of modified pectin: Pectinosomes have been shown to be a good candidate for metronidazole delivery system, owing to their mucoadhesive properties enabling them to have a longer residence time in the vagina. Modified pectin from various processes like $\mathrm{pH}$ and heat treated one were tested for its anticancer activity and it showed higher potency than normal pectin. The most well-known pectin is modified citrus pectin (MCP), which is prepared using inorganic acid $(\mathrm{HCl})$ and alkali $(\mathrm{NaOH})$, which lead to depolymerization of pectin and de-esterification of homogalacatan [71]. Similar changes were observed when enzymatic and chemical methods were used to modify pectin $[72,73]$.

Modified pectins anticancer activity is linked to induction of apoptosis and reducing proliferation of cancer cells [74-77]. MCP is commercially marketed as a nutraceutical and chemotherapeutic substance against several cancers [78]. In another study modified sweet potato pectin was shown to possess capacity to reduce cancer cell proliferation [79]. Low Degree of Polymerization (LDP) pectin have been shown to be more potent compared to high DP ones partly owing to their ability to be transported across intestinal wall and into the blood stream. Finally, oligo pectins are capable of inducing plant immunity, thus enabling plants to boost their immune system against pest attack. Prebiotics, oligo pectins have been shown to be better prebiotics for specific probiotic bacteria like Bifidobacteria and Lactobacilli. The selectivity of oligosaccharide depend on the chain length and presence of specific functional groups, the oligo pectins with short chain being preferred substrate for probiotics $[80,81]$.

\section{Carrageenan}

Carrageenan, a sulphated polysaccharide extracted from certain species of red seaweed [82]. Carrageenan exist in different forms of $\kappa$-kappa with single sulphate group, $\mathrm{i}$-iota with two sulphate groups and $\Lambda$-lambda with three sulphate groups. Carrageenan form thermoreversible gels with potassium ions or other metallic ions, it is also capable of forming gels with proteins hence often applied in chocolate milk and fresh cheese. Other applications include processed meats, dietetic formulations, infant formula, toothpaste, cosmetics, skin preparations and laxatives.

Sonication of carrageenan: A recently sonication of carrageenan solution was investigated at three frequencies of 23,48 and $83 \mathrm{kHz}$ at intensity of $50 \mathrm{~W}$. The group observed higher reduction in shear viscosity at $45 \mathrm{kHz}$ with full shear viscosity recovery on stopping ultrasound application, the other frequencies 23 and $83 \mathrm{kHz}$ had low effect, probably due to their inability to build effective bubbles and create cavitation due to low frequency at $23 \mathrm{kHz}$ and too high frequency at $83 \mathrm{kHz}$ respectively. During sonication free $\mathrm{OH}$-ions build up in the system, this is attributed to splitting of water molecules into hydroxyl and hydroxyl radical species.

In an earlier study carrageenan was degraded by sonication, the rate of degradation increased with increased intensity, time, and reduced $\mathrm{pH}$ and concentration [83]. K-carrageenan had a higher degradation rate compared to $\Lambda$-carrageenan; it is probably because the presence of additional sulphate groups in $\Lambda$ carrageenan could have contributed to its less vulnerability to sonication.

Possible application of carrageenan oligomers: Sonication offers an effective method of carrageenan oligomer processing. The carrageenan oligomers can be applied as plant growth promoter, antiviral, antitumor, antioxidants, anticoagulant, antithrombotic and hydrogels for burns dressings. Each function is linked to oligomers with specific molecular weight range [84].

\section{Guar gum}

Guar gum Guar gum is obtained from endosperm of the guar plant, Cyamopsis Tetragonolobus. Guar gum is a galactomannan with a linear backbone of $\beta$-D- $(1,4)$-mannose irregularly substituted by uncharged $\alpha$-D-(1, 6)-linked galactose side groups [85]. It is cold water soluble producing highly viscous pseudo plastic solution which makes it preferable choice in industry. Guar gum is industrially used as gelling, viscosifying and thickening agent. The viscosity of guar depends on the temperature, $\mathrm{pH}$, time, concentrations, degree of agitation, and particle size of the gum [86]. 
Sonication of guar gum: The only available study documented on sonication of guar gum is reported by Ansari et al., which revealed that Sonication could also be a convenient method of reducing the molecular weight of Guar Gum. Furthermore, the NMR results demonstrated that sonication did not alter the structural characteristics of the polymeric chain of guar gum. The depolymerization of Guar gum by sonication resulted in lower molecular weight fractions within three minutes of sonication the MW of initial GM decreased by half. Difference in water uptake and anisotropic elongation is also a significant achievement of sonication.

Applications of modified guar gum: The reduction of Guar Gum (GG) molecular weight for an appropriate modulation of its flow and gelling properties could ultimately be useful in pharmaceutical industries for innovative drug formulations, it could as well be applied in cosmetics and food industry.

\section{Chitin and chitosan}

Chitin a biopolymer consisting of poly $(\beta-(1 \rightarrow 4)-\mathrm{N}$-acetyl-Dglucosamine), it is a natural polysaccharide derived from several living organisms; chitin is the second most abundant polymer after cellulose in the world. Chitosan is the most significant derivative of Chitin obtained after partial deacylation, chitosan is a linear polysaccharide composed of $\beta$ - $(1 \rightarrow 4)$-linked 2-amino-2-deoxy-D-glucopyranose (GlcN, D-unit) and 2-acetamido-2-deoxy-D-glucopyranose (GlcNAc, A-unit) [87]

Sonication of chitin: Previously chitosan was prepared using chemical and enzymatic methods [88,89]. Investigation on impact of ultrasound on chitosan molecular weight and degree acetylation revealed that $1 \%$ Chitosan in $1 \%$ acetic acid solution was sonicated at $16.5,28.0$ and $35.2 \mathrm{Wcm}^{-2}$ for $0-30$ minutes, the researchers noted that the degree of acetylation was not changed while the molecular weight was reduced, the reduced sonication rate after optimum molecular weight reduction rate was attributed to many molecules with more bonds to be broken hence the rate of reducing molecular rate reduced with time after a given critical time limit. Finally, the group concluded that the effect of ultrasound was majorly affected by sonication time and power [90].

In another research to investigate the involvement of mechanochemistry and radical reaction during sonication to reduce chitosan molecular weight by employing ultrasound of $230 \mathrm{kHz}$ frequency and treatment time 0-90 minutes. Hydroxyl radicals contributed to approximately $60 \%$ of molecular weight reduction, the average sonolysis rate was $8 \times 10^{-11} \mathrm{~mol} \mathrm{~J}^{-1}$. Optimal molecular weight reduction was noted at 80 minutes and continuous treatment did not lead to further molecular weight reduction, this was attributed to increased number of molecules to be broken. The results further showed that degree of deacetylation of chitosan was not altered at all the power and time.

Moreover, Liu and co-workers sonicated shrimp shell chitosan at $800 \mathrm{C}, 250 \mathrm{~W}$ and $0-99 \mathrm{~h}$. The initial chitosan fractions had the following molecular weight $65.5 \times 10^{4} \mathrm{~K} \mathrm{Da}, 154 \times 10^{4} \mathrm{k} \mathrm{Da}, 77.5 \times 10^{4}$ $\mathrm{k} \mathrm{Da}$ and $44.7 \times 10^{4} \mathrm{k}$ Da and with de-acetylation degree DD\% 61.9, $72.1,87.1,91.6$ respectively. Results showed that chitosan with higher molecular weight and higher de-acetylation degree was more easily depolymerized, The DD degradation was inversely correlated, with the chitosan having DD $>90 \%$ having no detectable degradation while ones with $\mathrm{DD}<80 \%$ showed significant degradation. Besides, polydispersity decreased with treatment time [91].

Applications of chitosan: Chitosan is widely used in a range of diverse fields, including waste management, medicine, food and agriculture. Chitosan has biological properties such as biocompatibility, antimicrobial, biogradeable, mucoadhesion, anticholesterolemic and permeation enhancement effects [92,93]. The molecular weight of chitosan is a crucial factor in its functionality. Low molecular weight chitosan have been shown to possess much higher bioactivity than the large molecular weight ones. Some of the possible applications of sonicated chitosan are as follows:

Chitosan as antimicrobial agents: Ultrasonically treated chitosan showed a higher antimicrobial activity against known food pathogens; E. coli and S. aureus. The increased activity was attributed mainly to reduced molecular weight, particularly chitosan of molecular weight range of $5-10 \mathrm{~K} \mathrm{Da}$. The use of chitosan in bioactive packaging material against Pseudomonas aerouginosa and Staphylococcus aureus was explored; it showed effective anti-microbial activity [94].

Anti-diabetes mellitus: Low molecular weight chitosan with molecular weight of $20 \mathrm{kDa}$ has shown to lower the progression of diabetes mellitus. Other possible function of chitosan and oligochitosans include hypocholesterolemic, immune-stimulating, antitumor and anticancer effects. It also exhibits accelerating calcium and iron absorption, anti-inflammatory, antioxidant and AngiotensinI-converting enzyme (ACE) inhibitory activity-regulating blood pressure.

Food applications of chitosan: Chitosan is widely used in food industries as dietary fiber, lipids binding agents, preservative, thickener and stabilizer. It is also use as protective fungi static, antibacterial coating for fruit. Low molecular weight chitosan is used as nutraceuticals, antimycotic and antimicrobial agents. Moreover, chitosan carrageenan nano fibrils have shown a good potential to be used as nano composite packaging material [95].

Other biomedical applications: Chitosan has various biomedical applications like surgical sutures, dental implants, artificial skin, rebuilding of bone, corneal contact lenses, time release drugs for animals and humans encapsulating material. Besides, it equally possesses Immunological, mucoadhesive, antitumoral hemostatic and anticoagulant, healing, bacteriostatic ability. Chitosomes are also an excellent drug loading and delivering system [96].

\section{Starch}

Starch is of the most abundant natural polymer. It consists of amylose and amylopectin, starch is a partially crystalline polymeric substance. X-ray diffraction patterns of native starch granules may give A, B, C and V-type depending on the source of starch [97]. The molecular weight of starch is variable depending on its source. Starches and modified starches can be used to affect the physical properties of many foods [98].

Sonication of starch: Starch modification is achieved through different methods [99]. Acid and enzymatic modification of starch has been used to make nano-colloid or crystalline starch. It has been reported that ultrasonic treatment also reduced molecular weight of corn starch; the ability of ultrasound to degrade starch at $360 \mathrm{kHz}$ was shown to be mediated by $\mathrm{OH}$ - and mechano-chemical effects. Starch had a lower yield rate compared to chitosan because starch is highly branched while chitosan is linear. It was observed that chain breakage was directly related to time up to around 15 minutes thereafter the rate experienced slight decline.

In another study on the effect of ultrasonic on physical properties of corn starch, it was found that the gelatinization temperature was not 
changed. The rheological property of ultrasonic treated starch showed a reduced consistency coefficient. However, it is worth noting that the treatment was only done at two time points of 15 and 30 minutes, while in the previous studies impact of ultrasound was high after longer time treatment.

Effect of ultrasound on viscosity of various starches was investigated, sonication leads to marked reduced viscosity of waxy maize, tapioca, potato and sweet potato starches. Sonication decreased starch molecular size by de-polymerization, the rate of de-polymerization was high up to 30 minutes then it reduced gradually with time and nearly levels off after 60 minutes [100].

The first case of making nano starch particles using purely physical treatment was done by Bel Haaj and coworkers, the ultrasound was applied in waxy corn and standard starch, they observed conversion of starch into Nano sized particles with size range 100-200 nm using high intensity and long treatment time, moreover, much smaller nanoparticles less than $100 \mathrm{~nm}$ were generated with sonication for 60 minutes yielding $80 \mathrm{~nm}$ and 90 minutes. Moreover, the starch granular structure was destroyed after 75 minutes of sonication to $30 \mathrm{~nm}$.

Applications of low degree of polymerization (DP) starch: Sonicated starch generally has low degree of polymerization owing to depolymerization. Nano scale starch has been made by ultrasonic treatment; this creates materials for nano-starch applications like improved packaging materials. Nano composites to be used as fillers materials for biodegradable materials and packages. Additionally, Nano-starch improves the properties of packaging materials, it can also improve the structure and texture of foods where applied.

\section{Future Prospects of Ultrasonic in Polysaccharide}

The previous research results have shown not only the promising prospect of using ultrasound in polymer modification, but also in extraction of compounds [101] and processing [102,103]. Industries are always looking for innovative, affordable, effective and efficient methods of processing, modification and extraction of compounds [104-106]. Food and pharmaceutical ingredients industry can easily bank on the strengths of sonochemistry like; economical, more adaptable and easy to apply method with impact in various food systems which make it much better than enzymatic, chemical and other physical processes. Sonication does not suffer from the failure associated with enzymes and does not require cleaning steps associated with chemical treatments.

Polysaccharides being the most commonly used food ingredients but suffering from limited physico-chemical characteristics which limit their application, the need to modify is pressing. The growth of functional foods, pharmaceutical and cosmetic is driving sonication of polysaccharides. Search for innovative packaging materials: The need to have smart packaging with bioactive materials capable of controlling the internal condition of the product, preventing microbiological growth in the product $[107,108]$.

Nano technology in foods and ingredients: growth of nano ingredients in food sector is a driver of sonication since sonication is one of the effective methods of obtaining nano materials with varied applications. Search for novel Nano nutrient delivery systems with increased bioavailability [109]. Research on use of oligosaccharides in plant protection is gaining momentum and use of ultrasound to modify various polysaccharides into oligosaccharides. Innovations in ultrasonic machines have been going on with several equipment types adapted for different functions being developed and sold.

\section{Conclusions}

The future of sonochemistry is getting brighter with increasing research endeavors, good research results and up scaling in the discipline. Sonochemistry is a green technology which is cheaper, more adaptable, efficient and effective in several processes, it is most likely going to become one of the main technologies that will transform industries in the coming years. In summary, sonication is an effective and efficient method for polysaccharide modification and future oligosaccharide and nano scale molecules processing would mostly probably be done by sonication process. The sonolysis of the reviewed polysaccharides could be used to predict to some extent its activity in other polysaccharides like xanthan, alginate, carboxymethyl cellulose, konjac gum, gum arabica etc. Future study should be targeted at optimizing the sonication parameters, deeper understanding of mechanism, exploring sonicated products application and up-scaling the process.

\section{Acknowledgment}

The authors gratefully acknowledge the earmarked funds for the China Agriculture Research System (CARS-11-B-19). We also thank the Fundamental Research budget incremental project of Chinese Academy of Agricultural Sciences (2014ZL009).

\section{References}

1. Wrolstad RE (2012) In Food Carbohydrate Chemistry. John Wiley \& Sons, West Sussex, UK.

2. Izydorczyk M, Cui SW, Wang Q (2005) Polysaccharide Gums: Structures, Functional Properties, and Applications. Food Carbohydrates: Chemistry, Physical Properties, and Applications. Taylor \& Francis Group, CRC press Florida, USA.

3. Villarreal OM, Hernández AE, Arispuro VI, Tellez MAM (2012) Plant Cell Wall Polymers : Function, Structure and Biological Activity of Their Derivatives.

4. Rinaudo M (2006) Chitin and chitosa: Properties and applications. Progress in Polymers Science 31: 603-632.

5. Thakur BR, Singh RK, Handa AK (1997) Chemistry and uses of pectin--a review. Critical Reviews in Food Science and Nutrition 37: 47-73.

6. Funami T (2011) Next target for food hydrocolloid studies: Texture design of foods using hydrocolloid technology. Food Hydrocolloids 25:1904-1914.

7. Saha D, Bhattacharya S (2010) Hydrocolloids as thickening and gelling agents in food: a critical review. Journal of Food Science and Technology 47: 587-597.

8. Georgiev Y, Ognyanov M, Yanakieva I, Kussovski V, Kratchanova M (2012) Isolation, characterization and modification of citrus pectins. Journal of Biosciences and Biotechnology 1: 223-233.

9. Gumel AM, Annuar MSM, Heidelberg T (2013) Current application of controlled degradation processes in polymer modification and functionalization. Journal of Applied Polymer Science 129: 3079-3088.

10. Kurita O, Miyake Y, Yamazaki E (2012) Chemical modification of citrus pectin to improve its dissolution into water. Carbohydrate Polymers 87: 1720-1727.

11. Kentish S, Wooster TJ, Ashokkumar M, Balachandran S, Mawson R, et al (2008) The use of ultrasonics for nanoemulsion preparation. Innovative Food Science and Emerging Technologies 9: 170-175

12. Ostadzadeh M, Abbasi S, Ehsani MR (2012) Effects of ultrasound treatment on stability of cocoa-flavored milk. Iranian Journal of Nutrition Sciences \& Food Technology 7: 47-56

13. Avella M, DeVlieger JJ, Errico ME, Fischer S, Vacca P, et al. (2005) Biodegradable starch/clay nano composite films for food packaging applications. Food Chemistry 93: 467-474.

14. BelHaaj S, Magnin A, Petrier C, Boufi S (2013) Starch nanoparticles formation via high power ultrasonication. Carbohydrate Polymers 92: 1625-1632.

15. Lin N, Huang J, Chang PR, Anderson DP, Yu J (2011) Preparation, Modification, and Application of Starch Nanocrystals in Nanomaterials: A Review. Journal of Nanomaterials 1: 1-13. 
16. Shi L, Gunasekaran S (2008) Preparation of Pectin-ZnO Nanocomposite. Nanoscale Research Letters 3: 491-495.

17. Ansari SA, Matricardi P, Cencetti C, DiMeo C, Carafa M, et al. (2013) Sonication-based improvement of the physicochemical properties of Guar Gum as a potential substrate for modified drug delivery systems. BioMed Research International 2013: 01-11

18. Rastogi NK (2011) Opportunities and challenges in application of ultrasound in food processing. Critical Reviews in Food Science and Nutrition 51: 705-722.

19. Reich G (1998) Ultrasound-induced degradation of PLA and PLGA during microsphere processing: influence of formulation variables. European Journal of Pharmaceutics and Biopharmaceutics 45: 165-171.

20. Andersen T, Mattsson S, Tho I (2013) Pectosomes and Chitosomes as Delivery Systems for Metronidazole: The One Pot Preparation Method. Pharmaceutics 5: $445-456$.

21. Basedow AM, Ebert K H (1977) Ultrasonic Degradation of Polymers in Solution. Advances in Polymer Science 22: 83-148.

22. Hossein G, Keshavarz M, Ahmadi S, Naderi N (2013) Synergistic Effects of PectaSol-C Modified Citrus Pectin an Inhibitor of Galectin-3 and Paclitaxel on Apoptosis of Human SKOV-3 Ovarian Cancer Cells. Asian Pacific Journal of Cancer Prevention 14: 7561-7568.

23. Mason TJ (2010) Sonochemistry-a Proven Tool for Process Intensification. 20th International Congress on Acoustics, Sydney, Australia.

24. Jambrak AR, Herceg Z, Subaric D, Babic J, Brncic M, et al. (2010) Ultrasound effect on physical properties of corn starch. Carbohydrate Polymers 79: 91-100.

25. Leong T, Ashokkumar M, Sandra K (2011) The fundamentals of power ultrasound - A review. Acoustics Australia 39: 54-63.

26. Mason TJ (2007) Developments in ultrasound-non-medical. Progress in Biophysics and Molecular Biology 93: 166-175.

27. Chandrapala J, Oliver C, Kentish S, kumar MA (2012) Ultrasonics in food processing - Food quality assurance and food safety. Trends in Food Science and Technology 26: 88-98

28. Legay M, Gondrexon N, Le Person S, Boldo P, Bontemps A (2011) Enhancement of Heat Transfer by Ultrasound: Review and Recent Advances. International Journal of Chemical Engineering: 1-17.

29. Mason TJ, Paniwnyk L, Lorimer JP (1996) The uses of ultrasound in food technology. Ultrasonics Sonochemistry 3: 253-260.

30. Suslick KS, Price GJ (1999) Applications of Ultrasound to Materials Chemistry. Annual Review of Materials Science 29: 295-326.

31. Mohod AV, Gogate PR (2011) Ultrasonic degradation of polymers: effect of operating parameters and intensification using additives for carboxymethyl cellulose (CMC) and polyvinyl alcohol (PVA). Ultrasonics Sonochemistry 18: 727-734.

32. Mazzoccoli JP, Feke D, Blackwell J, Liu CC, Mann JA (2010) Ultrasonication of Polysaccharide Materials. Case Western Reserve University, USA.

33. Mirzaie A, Mohammadi T (2012) Effect of ultrasonic waves on flux enhancement in microfiltration of milk. Journal of Food Engineering 108: 77-86.

34. May PA, Moore JS, Silverman SK, Zimmerman SC, White SR (2013) Polymer Architecture Effects on Mechanochemical Reactions. University of Illinois at Urbana-Champaign, USA.

35. Chandrapala J, Oliver CM, Kentish S, Kumar AM (2013) Use of Power Ultrasound to Improve Extraction and Modify Phase Transitions in Food Processing. Food Reviews International 29: 67-91.

36. Gronroos A (2010) Ultrasonically Enhanced Disintegration: Polymers, Sludge and Contaminated Soil. University of Jyvaskyla, Finland.

37. Dolatowski ZJ, Stadnik J, Stasiak D (2007) Applications of ultrasound in food technology. ACTA Scientiarum Polonorum 6: 89-99.

38. Kardos N, Luche JL (2001) Sonochemistry of carbohydrate compounds. Carbohydrate Research 33: 115-131.

39. Kasaai MR (2013) Input power-mechanism relationship for ultrasonic Irradiation: Food and polymer applications. Natural Science 05: 14-22.

40. Anese M, De Bonis MV, Mirolo G, Ruocco G (2013) Effect of low frequency, high power pool ultrasonics on viscosity of fluid food: Modeling and experimental validation. Journal of Food Engineering 119: 627-632.

41. Kobus $Z$ (2008) Influence of physical properties of liquid on acoustic power of ultrasonic processor. TEKA Kom Mot Energ Roln-OI Pan 8: 71-78.

42. Liu D, Zhang $L$ (2013) The influence of ultrasound on the structure, rheological properties and degradation path of citrus pectin. The Journal of the Acoustical Society of America 133: 3595.

43. Ginsburg E, Kinsley MD, Quitral A (2009) The power of ultrasound. WILEY-VCH Verlag $\mathrm{GmbH}$ and Co. KGaA, Weinheim.

44. Buchholt HC, Christensen TMIE, Fallesen B, Ralet M-C, Thibault JF (2004) Preparation and properties of enzymatically and chemically modified sugar beet pectins. Carbohydrate Polymers 58: 149-161.

45. Cumpstey I (2013) Chemical Modification of Polysaccharides. ISRN Organic Chemistry, Hindawi Publishing Corporation, Newyork, USA.

46. Zhang L, Ye X, Xue SJ, Zhang X, Liu D, et al. (2013) Effect of high-intensity ultrasound on the physicochemical properties and nanostructure of citrus pectin. Journal of the Science of Food and Agriculture 93: 2028-2036.

47. Seshadri R, Weiss J, Hulbert GJ, Mount J (2003) Ultrasonic processing influences rheological and optical properties of high-methoxyl pectin dispersions. Food Hydrocolloids 17: 191-197.

48. Harding SE, Virum KM, Stokke BT, Smidsrod O (1991) Determination Molecular Of Polysaccharides. JAI Press Ltd.

49. Czechowska-Biskup R, Rokita B, Lotfy S, Ulanski P, Rosiak JM (2005) Degradation of chitosan and starch by $360-\mathrm{kHz}$ ultrasound. Carbohydrate Polymers 60: 175-184.

50. Camin NA, Perez OE, Pilosof AMR (2009) Molecular and functional modification of hydroxyl propyl methyl cellulose by high-intensity ultrasound. Food Hydrocolloids 23: 1089-1095.

51. Chen J, Liang RH, Liu W, Liu CM, Li T, et al. (2012) Degradation of highmethoxyl pectin by dynamic high pressure microfluidization and its mechanism. Food Hydrocolloids 28: 121-129.

52. Lii CY, Chen CH, Yeh Al, Lai VMF (1999) Preliminary study on the degradation kinetics of agarose and carrageenan's by ultrasound. Food Hydrocolloids 13 477-481.

53. Sanchez VJA, Motohiro T, Takaomi K (2013) Ultrasound effect used as external stimulus for viscosity change of aqueous carrageenan's. Ultrasonics Sonochemistry 20: 1081-1091.

54. Bonnin E, Garnier C, Ralet M (2014) Pectin-modifying enzymes and pectinderived materials : applications and impacts. Applied Microbial Biotechnology 98: 519-532.

55. Kim Y, Williams MAKK, Galant AL, Luzio GA Savary BJ, et al. (2013) Nano structural modification of a model homogalacturonan with a novel pectin methy esterase: Effects of $\mathrm{pH}$ on nanostructure, enzyme mode of action and substrate functionality. Food Hydrocolloids 33: 132-141.

56. Sorensen OS, Pauly M, Bush M, Skjot M, McCann MC, et al. (2000) Pectin engineering: modification of potato pectin by in vivo expression of an endo-1, 4-beta-D-galactanase. Proceedings of the National Academy of Sciences of the United States of America 97: 7639-7644.

57. Yuliarti O, Merino ML, Goh KT, Mawson J, Brennan C (2012) Characterization of gold kiwifruit pectin isolated by enzymatic treatment. International Journal of Food Science and Technology 47: 633-639.

58. Bhatia MS, Deshmukh R, Choudhari P, Bhatia NM (2008) Chemica Modification of Pectins, Characterization and Evaluation for Drug Delivery. Scientia Pharmaceutica 76: 775-784.

59. Awad TS, Moharram HA, Shaltout OE, Asker D, Youssef MM (2012) Applications of ultrasound in analysis, processing and quality control of food Food Research International 48: 410-427.

60. Zhang $L, Y e X$, Ding $T$, Sun $X, X u Y$, et al. (2013) Ultrasound effects on the degradation kinetics, structure and rheological properties of apple pectin. Ultrasonics Sonochemistry 20: 222-231.

61. Sotanaphun U, Chaidedgumjorn A, Kitcharoen N, Satiraphan M (2012) Preparation of Pectin from Fruit Peel of Citrus maxima. Silpakorn U Science and Tech 6: 42-48.

62. Bharath S, Deveswaran R (2013) Development of chemically modified pectin 
based. World journal of pharmacy and pharmaceutical sciences 2: 321-336.

63. Joannou KM, Price KL, Winyard PJ, Long DA (2011) Modified citrus pectin reduces galectin-3 expression and disease severity in experimental acute kidney injury. Plos One 6: e18683.

64. Leclere L, Cutsem PV, Michiels C (2013) Anti-cancer activities of pH- or heatmodified pectin. Frontiers in Pharmacology 4: 128.

65. Anuar NK, Wong TW, Taib MN (2012) Microwave modified non-crosslinked pectin films with modulated drug release. Pharmaceutical Development and Technology 17: 110-117

66. Kim Y, Williams MAK, Tzen JTC, Luzio GA, Galant AL, et al. (2014) Characterization of charged functional domains introduced into a modified pectic homogalacturonan by an acidic plant pectin methylesterase (Ficus awkeotsang Makino) and modeling of enzyme mode of action. Food Hydrocolloids 39: 319329.

67. Ruifeng M, Jianjun Z, Lifen Z, Xingqian Y, Donghong L (2012) Ultrasonic concentration measurement of citrus pectin aqueous solutions using $\mathrm{PC}$ and PLS regression. International Journal of Agriculture and Biological Engineering 5. $76-81$

68. Xu Y, Zhang L, Bailina Y, Ge Z, Ding T, et al. (2014) Effects of ultrasound and/ or heating on the extraction of pectin from grapefruit peel. Journal of Food Engineering 126: 72-81.

69. Kawasaki H, Takeda Y, Arakawa R (2007) Mass spectrometric analysis for high molecular weight synthetic polymers using ultrasonic degradation and the mechanism of degradation. Analytical Chemistry 79: 4182-4187.

70. Sivalingam G, Agarwal N, Madras G (2004) Distributed midpoint chain scission in ultrasonic degradation of polymers. AICHE Journal 50: 2258-2265.

71. Khotimchenko M, Kovalev V, Kolenchenko E, Khotimchenko Y (2012) Acidic Method for the Low Molecular Pectin Preparation. International Journal of Pharmacy and Pharmaceutical Sciences 4: 5-9.

72. Guess BW, Scholz MC, Strum SB, Lam RY, Johnson HJ, et al. (2003) Modified citrus pectin (MCP) increases the prostate-specific antigen doubling time in men with prostate cancer: a phase II pilot study. Prostate Cancer and Prostatic Diseases 6: 301-304

73. Inohara H, Raz A (1994) Effects of natural complex carbohydrate (citrus pectin) on murine melanoma cell properties related to galectin-3 functions. Glycoconjugate Journal 11: 527-532.

74. Glinsky VV, Raz A (2009) Modified citrus pectin anti-metastatic properties: one bullet, multiple targets. Carbohydrate Research 344: 1788-1791.

75. Jackson CL, Dreaden TM, Theobald LK, Tran NM, Beal TL, et al. (2007) Pectin induces apoptosis in human prostate cancer cells: correlation of a poptotic function with pectin structure. Glycobiology 17: 805-819.

76. Makker NP, Hogan V, Honjo Y, Baccarini S, Tait L, et al. (2002) Inhibition of human cancer cell growth and metastasis in nude mice by oral intake of modified citrus pectin. Journal of the National Cancer Institute 94: 1854-1862.

77. Yan J, Katz A (2010) PectaSol-C modified citrus pectin induces apoptosis and inhibition of proliferation in human and mouse androgen-dependent andindependent prostate cancer cells. Integrative Cancer Therapies 9: 197-203.

78. Ambrosino C, Tarallo R, Bamundo A, Cuomo D, Franci G, et al. (2010) Identification of a hormone-regulated dynamic nuclear actin network associated with estrogen receptor alpha in human breast cancer cell nuclei. Molecular \& Cellular Proteomics MCP 9: 1352-1367.

79. Zhang YY, Hua TM, Zhang M (2012) Effects of Modified Sweet Potato Pectins on the Proliferation of Cancer Cells. International Journal of Food Science \& Technology 48: 778-785.

80. Martin OE, Gibson GR, Rastall RA (2002) Comparison of the in vitro bifidogenic properties of pectins and pectic-oligosaccharides. Journal of Applied Microbiology 93: 505-511.

81. Onumpai C, Kolida S Bonnin E, Rastall RA (2011) Microbial utilization and selectivity of pectin fractions with various structures. Applied and Environmental Microbiology 77: 5747-5754.

82. Necas J, Bartosikova L (2013) Carrageenan : a review. Veterinarni Medicina 58: 187-205

83. Zhou C, Ma H (2006) Ultrasonic degradation of polysaccharide from red algae (Porphyra yezoensis).Journal of Agricultural and Food Chemistry 54: 22232228.
84. Abad LV (2010) Radiolysis studies of kappa carrageenan for bio based materials development. Department of Nuclear Engineering and Management, Philippines.

85. Tripathy S, Das MK (2013) Guar Gum: Present Status and Applications. Journa of Pharmaceutical and Scientific Innovation 4: 24-28.

86. Chudzikowski RJ (1971) Guar gum and its applications. Journal of the Society of Cosmetic Chemists 22: 43-60.

87. De Alvarenga ES (2011) Characterization and Properties of Chitosan Biotechnology of Biopolymers. Intech Publishers, Rijeka, Croatia.

88. Tommeraas K, Koping-Hoggard M, Varum KM, Christensen BE, Artursson P, et al. (2002) Preparation and characterization of chitosan's with oligosaccharide branches. Carbohydrate Research 337: 2455-2462.

89. Zhang H, Neau SH (2001) In vitro degradation of chitosan by a commercial enzyme preparation: effect of molecular weight and degree of deacetylation. Biomaterials 22: 1653-1658.

90. Baxter S, Zivanovic S, Weiss J (2005) Molecular weight and degree of acetylation of high-intensity ultrasonicated chitosan. Food Hydrocolloid 19: 821-830.

91. Liu H, Bao J, Du Y, Zhou X, Kennedy JF (2006) Effect of ultrasonic treatment on the biochemphysical properties of chitosan. Carbohydrate Polymers 64: 553559 .

92. Kumirska J, Weinhold MX, Thöming J, Stepnowski P (2011) Biomedical activity of chitin/chitosan based materials- influence of physicochemical properties apart from molecular weight and degree of N-Acetylation. Polymers 3: 18751901.

93. Xia W, Liu P, Zhang J, Chen J (2010) Biological activities of chitosan and chit oligosaccharides. Food Hydrocolloids 25: 170-179.

94. Coma V, Deschamps A, Gros MA (2003) Bioactive Packaging Materials from Edible Chitosan Polymer - Antimicrobial Activity Assessment on Dairy-Related Contaminants. Food science 68: 2788-2792.

95. Shankar S, Prasad J, Rhim J, Kim H (2014) Preparation, characterization, and antimicrobial activity of chitin nanofibrils reinforced carrageenan nano composite films. Carbohydrate Polymers 117: 468-475

96. Abreu F OMS, Forte MMC, Kist TBL, Honaiser LP (2010) Effect of the preparation method on the drug loading of alginate-chitosan microspheres. Express Polymer Letters 4: 456-464.

97. Herawati H (2012) Nano Crystalline Starch And Its Alternative Implementation. International Conference on Chemical and Material Engineering. Semarang Indonesia.

98. Thomas DJ, Atwell WA (1999) Starch Structure: Starches, American Association of Cereal Chemists International, USA.

99. Neelam K, Vijay S, Lalit S (2012) Various Techniques for the Modification of Starch and the Applications of its Derivatives. International Research Journal of Pharmacy 3: 25-31.

100. lida Y, Tuziuti T, Yasui K, Towata A, Kozuka T (2008) Control of viscosity in starch and polysaccharide solutions with ultrasound after gelatinization. Innovative Food Science \& Emerging Technologies 9: 140-146

101.Stankiewicz AI, Moulijn JA (2000) Process Intensification: Transforming Chemical Engineering. Chemical Engineering Progress.

102. Chisti Y (2003) Sonobioreactors: using ultrasound for enhanced microbia productivity. Trends in Biotechnology 21: 89-93.

103. Tiwari BK, Muthukumarappan K, O’Donnell CP, Cullen PJ (2009) Inactivation kinetics of pectin methyl esterase and cloud retention in sonicated orange juice. Innovative Food Science \& Emerging Technologies 10: 166-171.

104. Barreteau H, Delattre C, Michaud P (2006) Production of oligosaccharides as promising new food additive generation. Food Technology and Biotechnology 44: 323-333.

105. Srivastava P, Malviya R (2011) Sources of pectin, extraction and its applications in pharmaceutical industry-An overview. Indian Journal of Natural Products and Resources 2: 10-18.

106. Wu T, Zivanovic S, Hayes DG, Weiss J, Biopolymers F (2008) Efficien Reduction of Chitosan Molecular Weight by High-Intensity Ultrasound: Underlying Mechanism. Journal of Agricultural and Food Chemistry 56: 51125119. 
Citation: Ogutu FO, Mu T, Elahi R, Zhang M, Sun H (2015) Ultrasonic Modification of Selected Polysaccharides-Review. J Food Process Technol 6: 446. doi:10.4172/2157-7110.1000446

Page 8 of 8

107. Regiel A, Irusta S, Kyzioł A, Arruebo M, Santamaria J (2013) Preparation and characterization of chitosan-silver nanocomposite films and their antibacterial activity against Staphylococcus aureus. Nanotechnology, 24: 15-101.

108.Zhang K, Park B, Fang F, Choi HJ (2009) Sonochemical Preparation of
Polymer Nano composites. Molecules 14: 2095-2110.

109. Institute of Medicine Food Forum (2009) Nanotechnology in Food Products: Workshop Summary. National Academy of Sciences, Washington DC, USA 